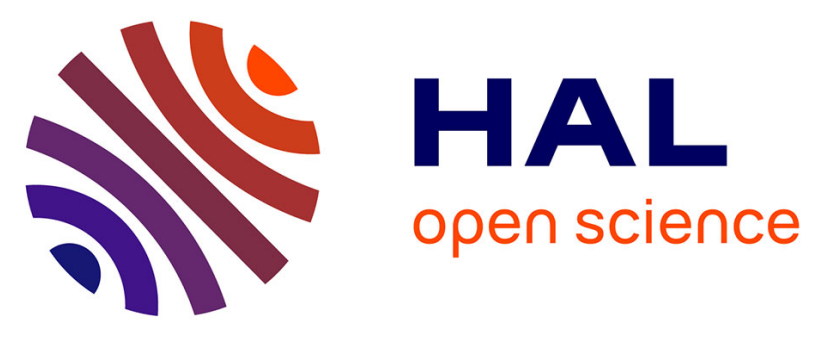

\title{
Microwave-Mediated Synthesis of Bulky Lanthanide Porphyrin-Phthalocyanine Triple-Deckers: Electrochemical and Magnetic Properties
}

Hong-Guang Jin, Xiaoqin Jiang, Irina A. Kühne, Sylvain Clair, Valérie Monnier, Christophe Chendo, Ghenadie Novitchi, Annie K. Powell, Karl M. Kadish, Teodor Silviu Balaban

\section{To cite this version:}

Hong-Guang Jin, Xiaoqin Jiang, Irina A. Kühne, Sylvain Clair, Valérie Monnier, et al.. Microwave-Mediated Synthesis of Bulky Lanthanide Porphyrin-Phthalocyanine Triple-Deckers: Electrochemical and Magnetic Properties. Inorganic Chemistry, 2017, 56 (9), pp.4864-4873. 10.1021/acs.inorgchem.6b03056 . hal-01683276

\section{HAL Id: hal-01683276 https://hal.science/hal-01683276}

Submitted on 16 Apr 2018

HAL is a multi-disciplinary open access archive for the deposit and dissemination of scientific research documents, whether they are published or not. The documents may come from teaching and research institutions in France or abroad, or from public or private research centers.
L'archive ouverte pluridisciplinaire HAL, est destinée au dépôt et à la diffusion de documents scientifiques de niveau recherche, publiés ou non, émanant des établissements d'enseignement et de recherche français ou étrangers, des laboratoires publics ou privés. 


\title{
Microwave-Mediated Synthesis of Bulky Lanthanide Porphyrin- Phthalocyanine Triple-Deckers: Electrochemical and Magnetic Properties
}

\author{
Hong-Guang Jin, ${ }^{* \dagger}{ }^{\dagger}$ Xiaoqin Jiang, ${ }^{\ddagger}$ Irina A. Kühne, ${ }^{\S \odot}$ Sylvain Clair, ${ }^{\|}$Valérie Monnier, ${ }^{\perp}$

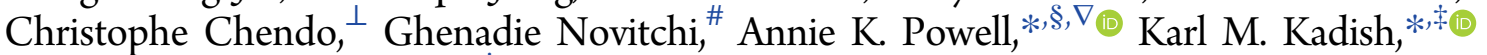 \\ and Teodor Silviu Balaban* ${ }^{\dagger}$
}

\footnotetext{
${ }^{\dagger}$ Aix Marseille University, CNRS UMR 7313, Centrale Marseille, Institut des Sciences Moléculaires de Marseille, Chirosciences, Service 442, Avenue Escadrille Normandie-Niemen, F-13397 Marseille Cedex 20, France

${ }^{\ddagger}$ Department of Chemistry, University of Houston, Houston, Texas 77204-5003, United States

${ }^{\S}$ Institut für Anorganische Chemie, Karlsruhe Institute of Technology (KIT), Engesserstraße 15, D-76131 Karlsruhe, Germany

"Aix Marseille University, CNRS UMR 7334, Institut Matériaux Microélectronique Nanosciences de Provence, F-13397 Marseille Cedex 20, France

${ }^{\perp}$ Aix Marseille University, CNRS FR 1739, Spectropole, Avenue Escadrille Normandie Niemen, F-13397 Marseille Cedex 20, France

${ }^{*}$ CNRS, UPR3228, Laboratoire National des Champs Magnétiques Intenses, F-38042 Grenoble, Cedex 9, France

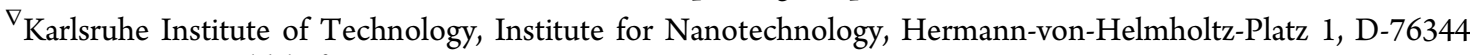

Eggenstein-Leopoldshafen, Germany
}

\begin{abstract}
Five heteroleptic lanthanide porphyrin-bisphthalocyanine triple-decker complexes with bulky peripheral groups were prepared via microwave-assisted synthesis and characterized in terms of their spectroscopic, electrochemical, and magnetic properties. These compounds, which were easily obtained under our preparative conditions, would normally not be accessible in large quantities using conventional synthetic methods, as a result of the low yield resulting from steric congestion of bulky groups on the periphery of the phthalocyanine and porphyrin ligands. The electrochemically

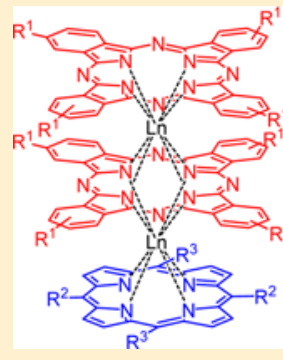

(Pc) $\operatorname{Ln}(\mathrm{Pc}) \operatorname{Ln}($ Por $)$ TD-2, Ln $=$ Gd

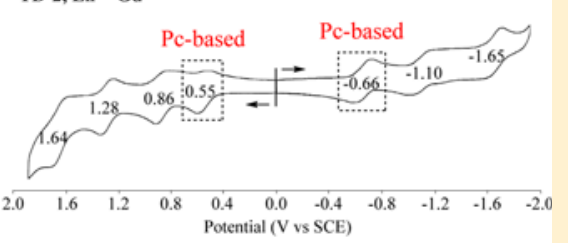
investigated triple-decker derivatives undergo four reversible one-electron oxidations and three reversible one-electron reductions. The sites of oxidation and reduction were assigned on the basis of redox potentials and UV-vis spectral changes during electron-transfer processes monitored by thin-layer spectroelectrochemistry, in conjunction with assignments of electronic absorption bands of the neutral compounds. Magnetic susceptibility measurements on two derivatives containing $\mathrm{Tb}^{\mathrm{III}}$ and $\mathrm{Dy}{ }^{\mathrm{III}}$ metal ions reveal the presence of ferromagnetic interactions, probably resulting from magnetic dipolar interactions. The $\mathrm{Tb}^{\mathrm{III}}$ derivative shows SMM behavior under an applied field of $0.1 \mathrm{~T}$, where the direct and Orbach process can be determined, resulting in an energy barrier of $U_{\text {eff }}=132.0 \mathrm{~K}$. However, Cole-Cole plots reveal the presence of two relaxation processes, the second of which takes place at higher frequencies, with the data conforming to a $1 / t \propto T^{7}$ relation, thus suggesting that it can be assigned to a Raman process. Attempts were made to form two-dimensional (2D) self-assembled networks on a highly oriented pyrolytic graphite (HOPG) surface but were unsuccessful due to bulky peripheral groups on the two Pc macrocycles.
\end{abstract}

\section{INTRODUCTION}

Triple-decker complexes containing tetrapyrrolic phthalocyanine $(\mathrm{Pc})$ and/or porphyrin (Por) macrocycles have been used in applications related to their characteristic properties, which are more than the sum of their compositional parts. Examples of applications for these types of compounds include molecular-level information storage, ${ }^{1}$ field effect transistors, ${ }^{2}$ and single-molecule magnets. ${ }^{3}$

In an early synthesis of heteroleptic triple-decker complexes with Pc and Por macrocycles, ${ }^{4}$ the $(\mathrm{Pc}) \operatorname{Ln}(\mathrm{Pc}) \operatorname{Ln}($ Por) unit was shown to be accessible according to the procedure of Weiss. ${ }^{5}$ In this synthetic method, a presynthesized doubledecker $(\mathrm{Pc}) \operatorname{Ln}(\mathrm{Pc})$ unit reacted with the in situ (Por) $\operatorname{Ln}(\mathrm{acac})_{3}$ (acac $=$ acetylacetonate $)$ formed by refluxing the porphyrin (Por) with excess $\operatorname{Ln}(\mathrm{acac})_{3}$ in 1,2,4-trichlorobenzene (TCB). However, the yield via this procedure was low due to the harsh conditions of high temperature (bp. TCB, $214^{\circ} \mathrm{C}$ ) and rather 
long reaction times (ca. $12 \mathrm{~h}$ ). Moreover, this reaction barely occurred when there was steric congestion resulting from bulky groups on the periphery of the porphyrin and phthalocyanine macrocycles in the targeted triple-deckers. ${ }^{6}$

Mixed porphyrin/phthalocyanine triple-decker compounds of the type $(\mathrm{Pc}) \operatorname{Ln}\left(\mathrm{Pc}_{\mathrm{c}}\right) \operatorname{Ln}($ Por $)$ are similar to other types of triple-decker tetrapyrrole complexes in that they exhibit a large number of oxidation states, reversible electrochemistry, and relatively low oxidation potentials. ${ }^{4,7}$ However, to the best of our knowledge, there have been no reports in the literature which have assigned the probable sites of electron transfer for oxidation or reduction of these complexes. The magnetic behavior of heteroleptic $(\mathrm{Pc}) \operatorname{Ln}(\mathrm{Pc}) \operatorname{Ln}($ Por) derivatives has also not been studied in detail, ${ }^{3 a}$ as is the case for their doubleand quadruple-decker conterparts, ${ }^{8}$ particularly in terms of the effect of the central lanthanide ions on molecular magnetism.

Both of these points are addressed in the current paper, which describes the design and synthesis of five new tripledecker complexes (Pc) $\operatorname{Ln}(\mathrm{Pc}) \operatorname{Ln}$ (Por) with bulky substituents on the macrocycles, four of which (TD-1-TD-4) are characterized in terms of their spectroscopic and electrochemical properties. The single-molecule magnetic behavior for two of the compounds is also demonstrated.

The structures of the investigated compounds, labeled as TD-1-TD-5, are shown in Scheme 1 and were prepared by

\section{Scheme 1. Synthetic Route for Triple-Decker Complexes} TD-1-TD-5

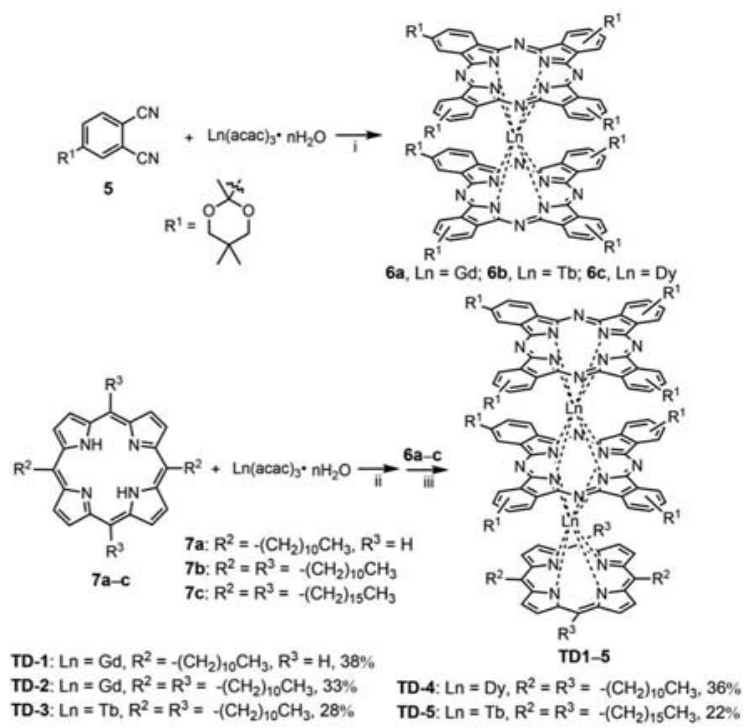

${ }^{a}$ Reaction conditions: (i) 1-pentanol/DBU, $140{ }^{\circ} \mathrm{C}$, overnight; (ii) $\mathrm{DCB}$, microwave, $180^{\circ} \mathrm{C}, 10 \mathrm{~min}, 10 \mathrm{bar}, 150 \mathrm{~W}$; (iii) microwave, 220 ${ }^{\circ} \mathrm{C}, 30 \mathrm{~min}, 17 \mathrm{bar}, 250 \mathrm{~W}$. Yields are based on the cumulative procedures (ii) and (iii).

microwave irradiation, a practical methodology that minimizes tedious isolation from other scrambled macrocyclic products. By combining spectroscopic and electrochemical methods to characterize the final synthetic products, we are able to discern how the number of undecyl substituents introduced at the meso positions of the porphyrin ring will influence the electronic absorption spectra, redox potentials, and perhaps also the site of electron transfer in the porphyrin-phthalocyanine heteroleptic complexes.
Although we were unable to obtain ordered self-assembled monolayers on a highly oriented pyrolytic graphite (HOPG) surface for imaging by scanning tunneling microscopy (STM) at the liquid-solid interface, we are confident that such complexes may find applications once better grafting groups have been added to the molecules.

\section{RESULTS AND DISCUSSION}

Design and Synthesis. 4-(2,5,5-Trimethyl-1,3-dioxan-2yl)phthalodinitrile 5, ${ }^{9}$ free-base meso-di- and meso-tetraundecylporphyrins $7 \mathbf{a}, \mathbf{b}$ and meso-tetrahexadecylporphyrin $7 \mathrm{c}^{10}$ were prepared according to published procedures. The conventional Weiss $\operatorname{method}^{5}$ was initially employed to prepare the tripledecker complexes TD-1 and TD-2 (Scheme 1). The precursor 5 and $\mathrm{Gd}(\mathrm{acac})_{3} \cdot 2 \mathrm{H}_{2} \mathrm{O}$ were reacted in the presence of diazabicycloundecene (DBU) to synthesize the double-decker 6a, whose spectrum is shown in Figure S1 in the Supporting Information. The yield of this reaction was comparable to yields reported for similar double-decker complexes. ${ }^{11}$

The free-base porphyrin, $7 \mathbf{a}$ or $7 \mathbf{b}$, was admixed with $\mathrm{Gd}(\mathrm{acac})_{3} \cdot 2 \mathrm{H}_{2} \mathrm{O}$ and heated to reflux in TCB for $4 \mathrm{~h}$, and $\mathbf{6 a}$ was then added after cooling the reaction mixture to room temperature. This was followed by prolonged heating and refluxing for up to $20 \mathrm{~h}$. However, as shown in the lowresolution mass spectra (Figures S2 and S3 in the Supporting Information), only very weak ion peaks attributed to the desired TD-1 or TD-2 products could be detected, while strong ion peaks attributed to the unreacted starting compound $\mathbf{6 a}$ are observed. This implies that the reaction occurred but only in a low single-digit yield, making it impossible to collect, purify, and fully characterize these target compounds due to the small amount of the sample obtained by this method.

As mentioned above, heteroleptic triple-decker compounds with bulky groups on the periphery of the porphyrin and/or phthalocyanine macrocycle are obtained in low yield when using the published synthetic method. ${ }^{6}$ For example, Lindsey and co-workers tried but failed to prepare a triple-decker complex utilizing the standard procedure with (THP)Eu(acac) $\left(\mathrm{THPH}_{2}=\right.$ meso-tetraheptylporphyrin $)$ and $\left[(\text { heptyl })_{8} \mathrm{Pc}\right]_{2} \mathrm{Eu}$. The authors invoked steric hindrance of the peripheral alkyl groups on the porphyrin and phthalocyanines to explain the low reactivity. ${ }^{6 \mathrm{~b}}$

To circumvent this drawback, we employed microwave irradiation in a professional oven equipped with a video camera to monitor color changes and/or precipitation, thus avoiding prolonged reaction times. $o$-Dichlorobenzene (DCB) was chosen as an alternative solvent to trichlorobenzene (TCB) due to its lower boiling point, thus being easier to remove and favoring microwave absorbance. The optimized microwave conditions for stages ii and iii are given in Scheme 1. Under these conditions, TD-1-TD-5 were obtained in relatively larger yields after flash chromatography $(38,33,28,36$, and $22 \%$, respectively). The double-deckers $6 a-c$ could also be rapidly prepared using microwave irradiation at $140{ }^{\circ} \mathrm{C}$, under the conditions of $15 \mathrm{~min}, 17 \mathrm{bar}$, and $250 \mathrm{~W}$. The mass spectrum of the product (see the Supporting Information) shows typical isotopic profiles of the lanthanide atoms $(\mathrm{Gd}, \mathrm{Tb}$, and Dy) and clearly confirms the elemental composition of these triple-decker compounds.

Electronic Absorption Spectra. Electronic absorption spectra of these triple-decker complexes were recorded in $\mathrm{CHCl}_{3}$ (Figure 1) and $\mathrm{PhCN}$ (Figure S4 in the Supporting Information), and the spectral data are summarized in Table 1. 


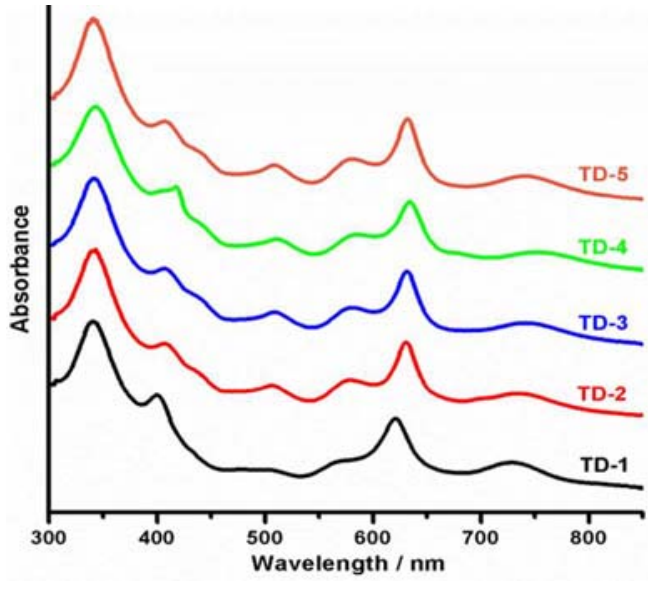

Figure 1. UV-vis absorption spectra of TD-1-TD-5 recorded in $\mathrm{CHCl}_{3}\left(c=8.5 \times 10^{-6} \mathrm{~mol} / \mathrm{L}\right)$.

The UV-vis absorption characteristics of TD-1-TD-5 are similar to each other due to their similar molecular structures, which are characterized by two phthalocyanines and one porphyrin connected by two lanthanide ions. As seen in Figure 1 and Table 1 , the strong bands in the region of spectrum at 341-344 and $400-418 \mathrm{~nm}$ in $\mathrm{CHCl}_{3}$ are attributed mainly to the Soret bands of the phthalocyanine and the porphyrin macrocycle, respectively. The $\mathrm{Q}$ bands of the compounds at 506-511, 579-584, and 621-634 $\mathrm{nm}$ are assigned as arising mainly from the two neighboring Pc ligands in the $\left[\left(\mathrm{Pc}^{2-}\right)\right.$ $\left.\mathrm{Ln}\left(\mathrm{Pc}^{2-}\right)\right]$ part of the molecule. The $\mathrm{Q}$ band absorption at $728-749 \mathrm{~nm}$ is mainly associated with the Pc ligand, together with some contributions from the Por ligand. These wavelengths are very similar to published wavelengths of analogous triple-decker sandwich complexes. ${ }^{12}$

Three of the six bands in Figure 1 and Table 1 vary with the number of meso substituents on the porphyrin macrocycle, while three do not. The Soret and Q bands of TD-1 and TD-2 at $400-406,621-631$, and $728-735 \mathrm{~nm}$ in $\mathrm{CHCl}_{3}$ are sensitive to the $\mathrm{R}^{2}$ and $\mathrm{R}^{3}$ substituents on the porphyrin ligand, while the three strong bands at $341-343,506-507$, and $579-580 \mathrm{~nm}$ are almost independent of these substituents. This can be seen by comparing the spectra shown in Figure 1 for TD-1 and TD-2, which differ in the number of meso-substituted undecyl groups on the porphyrin macrocycle; TD-1 has two meso-undecyl groups, while TD-2 has four. The three bands of TD-1 at 400, 621, and $728 \mathrm{~nm}$ in $\mathrm{CHCl}_{3}$ are shifted to 406, 631, and $735 \mathrm{~nm}$ for TD-2 under the same solution conditions. The same trends in electronic absorption spectra are observed in $\mathrm{PhCN}$ as in $\mathrm{CHCl}_{3}$.

A $15 \mathrm{~nm}$ difference in the position of the Soret band is seen in Figure S6 in the Supporting Information between monomeric porphyrin $7 \mathbf{a}\left(\lambda_{\max } 404 \mathrm{~nm}\right)$ and $7 \mathbf{b}\left(\lambda_{\max } 419\right.$ $\mathrm{nm})$, which are used to synthesize TD-1 and TD-2 to TD-4, respectively, confirming our assignment of the 400 and $406 \mathrm{~nm}$ bands in TD-1 and TD-2 as porphyrin-based. Furthermore, similar positions of the peaks for TD-2 and TD-3 at 343, 406407, 507-508, 579-581, and $631 \mathrm{~nm}$ in $\mathrm{CHCl}_{3}$ indicate a lack of sensitivity of these bands to the lanthanide metal ions of the compounds, in this case Gd and Dy.

From the above analysis, it is thus possible to assign the 400-418 nm band in $\mathrm{CHCl}_{3}$ as being porphyrin-based and all the other bands, at 341-344, 506-511, 579-585, 621-634, and 728-749 nm, as phthalocyanine-based. The same assignments can be made for the absorption bands in $\mathrm{PhCN}$ and, in combination with the data from electrochemistry and spectroelectrochemistry, will provide indirect evidence for the site of oxidation or reduction being predominantly porphyrinor phthalocyanine-based in a specific redox process.

Electrochemistry. The electrochemical behavior of TD-1TD-4 was studied by cyclic voltammetry in PhCN containing $0.1 \mathrm{M}$ TBAP. Under these solution conditions, each compound exhibits four one-electron oxidations and three one-electron reductions (Figure 2), all of which are attributed to ligandbased processes. The measured half-wave potentials are given in Table 2 along with $E_{1 / 2}$ values taken from the literature for reduction and oxidation of related triple-decker complexes having only phthalocyanine or only porphyrin macrocycles. An illustration showing the structures of these compounds with substituents on the macrocycles is given in Scheme 2.

The reductions of monomeric phthalocyanines ${ }^{13}$ are significantly easier than reductions of monomeric porphyrins ${ }^{14}$ having the same central metal ions, and the same trend is observed when the electrochemical data for TD-1-TD-4 are compared with those of the related homoleptic $\operatorname{Ln}_{2}(\mathrm{Pc})_{3}{ }^{7 \mathrm{~b}}$ and $\mathrm{Ln}_{2}$ (Por) ${ }_{3}{ }^{15}$ triple-deckers. For example, the three $\operatorname{Ln}_{2}(\mathrm{OEP})_{3}$ derivatives undergo only a single one-electron reduction in $\mathrm{CH}_{2} \mathrm{Cl}_{2}$ at $E_{1 / 2}=-1.67$ or $-1.68 \mathrm{~V}$ vs $\mathrm{SCE}^{15}$ while the three $\mathrm{Ln}_{2}(\mathrm{Pc})_{3}$ complexes exhibit three one-electron reductions within the same potential range, the first of which is located at $E_{1 / 2}=-1.38$ to $-1.42 \mathrm{~V}$ vs SCE, ${ }^{15}$ as seen in Table 2 . The first two reductions of $\mathrm{Ln}_{2}(\mathrm{Pc})_{3}$ (compounds TD-6-TD-8) have $E_{1 / 2}$ values almost identical with those for compounds in

Table 1. Electronic Absorption Data of TD-1-TD-5 in $\mathrm{CHCl}_{3}$ and $\mathrm{PhCN}$ with Assignment of Bands to Specific Macrocycles

\begin{tabular}{|c|c|c|c|c|c|c|c|c|}
\hline \multirow[b]{2}{*}{ solvent } & \multirow[b]{2}{*}{ triple-decker } & \multirow[b]{2}{*}{$\operatorname{Ln}$} & \multicolumn{6}{|c|}{$\lambda_{\max } / \mathrm{nm}(\log \varepsilon)$} \\
\hline & & & Pc & Por & $\mathrm{Pc}$ & Pc & $\mathrm{Pc}$ & $\mathrm{Pc}$ \\
\hline \multirow[t]{5}{*}{$\mathrm{CHCl}_{3}$} & TD-1 & $\mathrm{Gd}$ & $341(5.16)$ & $400(4.92)$ & $506(4.33)$ & $580(4.44)^{a}$ & $621(4.80)$ & $728(4.43)^{a}$ \\
\hline & TD-2 & $\mathrm{Gd}$ & $343(5.20)$ & $406(4.86)$ & $507(4.55)$ & $579(4.60)$ & $631(4.87)$ & $735(4.43)^{a}$ \\
\hline & TD-3 & $\mathrm{Tb}$ & $343(5.18)$ & $407(4.86)$ & $508(4.45)$ & $581(4.59)$ & $631(4.85)$ & $742(4.39)^{a}$ \\
\hline & TD-4 & Dy & $344(5.21)$ & $418(4.93)$ & $511(4.58)$ & $584(4.63)$ & $634(4.86)$ & $749(4.41)^{a}$ \\
\hline & TD-5 & $\mathrm{Tb}$ & $341(5.23)$ & $407(4.87)$ & 509 (4.59) & $581(4.64)$ & $632(4.90)$ & $741(4.45)^{a}$ \\
\hline \multirow[t]{5}{*}{$\mathrm{PhCN}$} & TD-1 & $\mathrm{Gd}$ & $343(5.02)$ & $402(4.79)$ & $504(4.18)$ & $581(4.27)^{a}$ & $622(4.64)$ & $734(4.22)^{a}$ \\
\hline & TD-2 & $\mathrm{Gd}$ & $343(5.08)$ & $410(4.95)$ & $513(4.47)$ & $582(4.49)$ & $633(4.75)$ & $744(4.27)^{a}$ \\
\hline & TD-3 & $\mathrm{Tb}$ & $342(5.11)$ & $409(4.81)$ & $514(4.48)$ & $584(4.47)$ & $633(4.74)$ & $745(4.45)^{a}$ \\
\hline & TD-4 & Dy & $344(5.09)$ & $416(4.77)$ & $514(4.47)$ & $585(4.45)$ & $636(4.71)$ & $752(4.22)^{a}$ \\
\hline & TD-5 & $\mathrm{Tb}$ & $344(5.15)$ & $410(4.85)$ & $511(4.56)$ & $583(4.59)$ & $634(4.80)$ & $745(4.41)^{a}$ \\
\hline
\end{tabular}

${ }^{a}$ Broad band. 


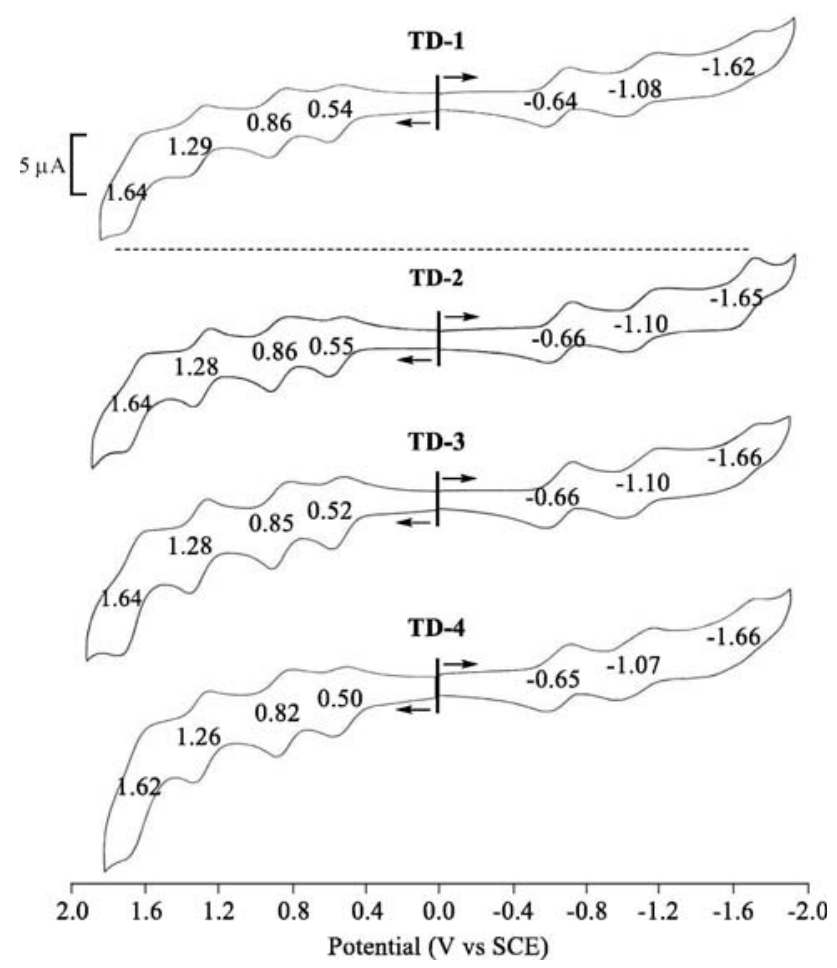

Figure 2. Cyclic voltammograms of TD-1-TD-4 in PhCN with $0.1 \mathrm{M}$ TBAP.

the series of $(\mathrm{Pc}) \operatorname{Ln}(\mathrm{Pc}) \operatorname{Ln}($ Por) (TD-1-TD-4), which are reduced at -0.64 to $-0.66 \mathrm{~V}$ in the first step and -1.08 to $-1.10 \mathrm{~V}$ in the second.

The difference in potentials between the first oxidation of monomeric porphyrins and monomeric phthalocyanines with the same central metal ions is not as large as in the case of reductions, ${ }^{13,14}$ and thus one cannot easily assign the site of electron transfer for the first oxidation of the monomeric macrocycles on the basis of $E_{1 / 2}$ values alone. The same is true for compounds in the triple-decker series, where the first oxidations of the $\operatorname{Ln}_{2}(\mathrm{OEP})_{3}$ derivatives (TD-9-TD-11) are easier than the first oxidation of the $\operatorname{Ln}_{2}(\mathrm{Pc})_{3}$ species by an average of $115 \mathrm{mV}$; however, as seen in Table 2, much smaller differences in $E_{1 / 2}$ are observed when potentials are compared
Scheme 2. Structures for Three Groups of Triple-Decker Complexes: (a) from This Work; (b) from Ref $7 \mathrm{~b}$; and (c) from Ref $15^{a}$

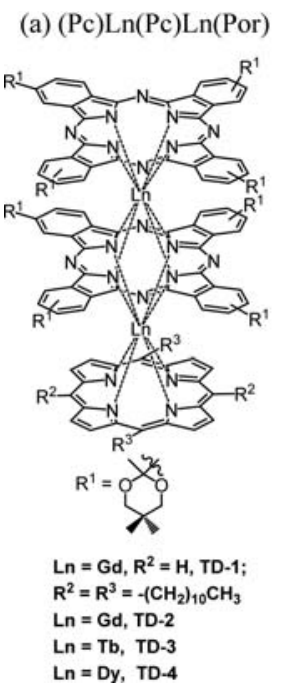

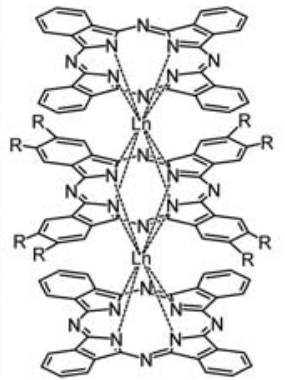

$\mathrm{R}=\mathrm{OC}_{8} \mathrm{H}_{17}$

$\mathrm{Ln}=\mathrm{Gd}, \mathrm{TD}-6$ $\mathrm{Ln}=\mathrm{Tb}, \mathrm{TD}-7$ $\operatorname{Ln}=\mathrm{Dy}, \mathrm{TD}-8$ (b) $\mathrm{Ln}_{2}(\mathrm{Pc})_{3}$ (c) $\mathrm{Ln}_{2}(\mathrm{Por})_{3}$

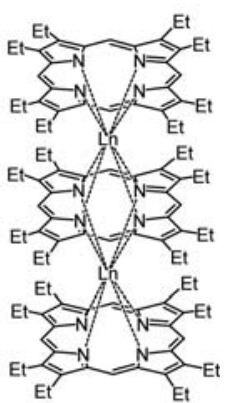

$\operatorname{Ln}=\mathrm{Eu}, \mathrm{TD}-9$ $\operatorname{Ln}=\mathrm{La}, \mathrm{TD}-10$ $\mathrm{Ln}=\mathrm{Ce}, \mathrm{TD}-11$
${ }^{a_{\text {The }}}$ measured redox potentials are given in Table 2 .

for the second, third, and fourth oxidations of triple-decker compounds in the series of $\operatorname{Ln}_{2}(\mathrm{Pc})_{3}$ (TD-6-TD-8) with those of $\operatorname{Ln}_{2}(\mathrm{OEP})_{3}$ (TD-9-TD-11).

Although no significant differences can be seen between $E_{1 / 2}$ values for the second oxidation of compounds in the $\mathrm{Ln}_{2}(\mathrm{OEP})_{3}$ and $\operatorname{Ln}_{2}(\mathrm{Pc})_{3}$ series (where $E_{1 / 2}$ values range from 0.59 to $0.67 \mathrm{~V}$ ), these potentials are all more negative than $E_{1 / 2}$ values for the second oxidation of TD-1-TD-4, where the half-wave potentials range from 0.82 to $0.87 \mathrm{~V}$.

Finally, it should be noted that half-wave potentials for the third and fourth oxidations of TD-1-TD-4 are virtually the same as $E_{1 / 2}$ values for the third and fourth oxidations of TD6-TD-8, the latter of which must be Pc-based in the $\mathrm{Ln}_{2}(\mathrm{Pc})_{3}$ series by virtue of the fact that no porphyrin ligands are present in the compounds.

In summary, the above analysis of the electrochemical data is consistent with the first reduction at one or both of the Pc ligands in TD-1-TD-4 and also with the first oxidation at one or both of the Pc ligands in the same series of compounds.

Table 2. Half-Wave Potentials and Assignment of Site of Electron Transfer for Reduction and Oxidation of TD-1-TD-4 in $\mathrm{PhCN}$ and of Reference Compounds TD-6-TD-11 in $\mathrm{CH}_{2} \mathrm{Cl}_{2}{ }^{a}$

\begin{tabular}{|c|c|c|c|c|c|c|c|c|c|c|c|c|}
\hline \multirow[b]{3}{*}{ compd label } & \multirow[b]{3}{*}{$\operatorname{compd}^{b}$} & & & & & & \multicolumn{4}{|c|}{ reduction } & \multirow[b]{3}{*}{ H-L gap } & \multirow[b]{3}{*}{ ref } \\
\hline & & \multicolumn{5}{|c|}{ oxidation } & \multicolumn{3}{|c|}{ Pc } & \multirow[b]{2}{*}{ fourth Por } & & \\
\hline & & fifth & fourth & third & second & first $\mathrm{Pc}$ & first & second & third & & & \\
\hline TD-2 & (Pc) Gd(Pc)Gd(Por) & & 1.63 & 1.28 & 0.87 & 0.54 & -0.66 & -1.10 & & -1.65 & 1.20 & this work \\
\hline TD-3 & $(\mathrm{Pc}) \mathrm{Tb}(\mathrm{Pc}) \mathrm{Tb}$ (Por) & & 1.61 & 1.26 & 0.82 & 0.50 & -0.65 & -1.06 & & -1.66 & 1.15 & this work \\
\hline TD-4 & (Pc)Dy(Pc)Dy(Por) & & 1.65 & 1.28 & 0.85 & 0.52 & -0.66 & -1.10 & & -1.66 & 1.18 & this work \\
\hline TD-7 & $(\mathrm{Pc}) \mathrm{Tb}(\mathrm{Pc}) \mathrm{Tb}(\mathrm{Pc})$ & & 1.60 & 1.22 & 0.66 & 0.30 & -0.70 & -1.04 & -1.38 & & 1.00 & $7 \mathrm{~b}$ \\
\hline TD-8 & $(\mathrm{Pc}) \operatorname{Dy}(\mathrm{Pc}) \operatorname{Dy}(\mathrm{Pc})$ & & 1.61 & 1.22 & 0.64 & 0.29 & -0.68 & 1.03 & -1.38 & & 0.97 & $7 \mathrm{~b}$ \\
\hline TD-9 & $\mathrm{Eu}_{2}(\mathrm{OEP})_{3}$ & & 1.55 & 1.16 & 0.59 & $0.13^{c}$ & & & & -1.68 & 1.81 & 15 \\
\hline TD-10 & $\mathrm{La}_{2}(\mathrm{OEP})_{3}$ & & 1.45 & 1.10 & 0.65 & $0.25^{c}$ & & & & -1.67 & 1.92 & 15 \\
\hline TD-11 & $\mathrm{Ce}_{2}(\mathrm{OEP})_{3}$ & & 1.36 & 1.06 & 0.64 & $0.19^{c}$ & & & & -1.67 & 1.86 & 15 \\
\hline
\end{tabular}

${ }^{a}$ The porphyrin and phthalocyanine ring substituents are identified in Scheme $2 .{ }^{b}$ See structures in Scheme $2 .{ }^{c}$ The first oxidation is not Pc-based for $\mathrm{Ln}_{2}(\mathrm{OEP})_{3}$, which contains only porphyrin macrocycles. 
In this regard, it should be noted that the experimentally measured HOMO-LUMO gaps of TD-1-TD-4 range from 1.15 to $1.20 \mathrm{~V}$ in $\mathrm{PhCN}$, values which are about $100 \mathrm{mV}$ larger than the HOMO-LUMO gaps reported for an earlier characterized series of $(\mathrm{Pc}) \operatorname{Ln}(\mathrm{Pc}) \operatorname{Ln}($ Por $)$ compounds $^{16}$ and $200 \mathrm{mV}$ larger than the HOMO-LUMO gaps for compounds in the $\operatorname{Ln}_{2}(\mathrm{Pc})_{3}$ series TD-6-TD-8, where $\Delta E_{1 / 2}$ ranges from 0.97 to $1.03 \mathrm{~V}$, as seen in Table 2 .

Significantly, however, the HOMO-LUMO gaps for the three $\operatorname{Ln}_{2}(\mathrm{OEP})_{3}$ compounds (TD-9-TD-11) range from 1.81 to $1.92 \mathrm{~V}$, consistent with a difference in the site of electron transfer between the triple-decker derivatives with three OEP macrocycles and those with three Pc macrocycles (TD-6-TD8) or those with two Pc and one Por macrocycle (TD-1-TD4).

Thin-layer UV-vis spectroelectrochemistry, ${ }^{17,18}$ in combination with assignments of electronic absorption bands for the neutral compounds in the series of TD-1-TD-4, was utilized to elucidate and confirm the site of electron transfer proposed above for the first oxidation and first reduction of the tripledecker compounds. Examples of the spectral changes are given in Figure 3 and Figures S7-S9 in the Supporting Information,
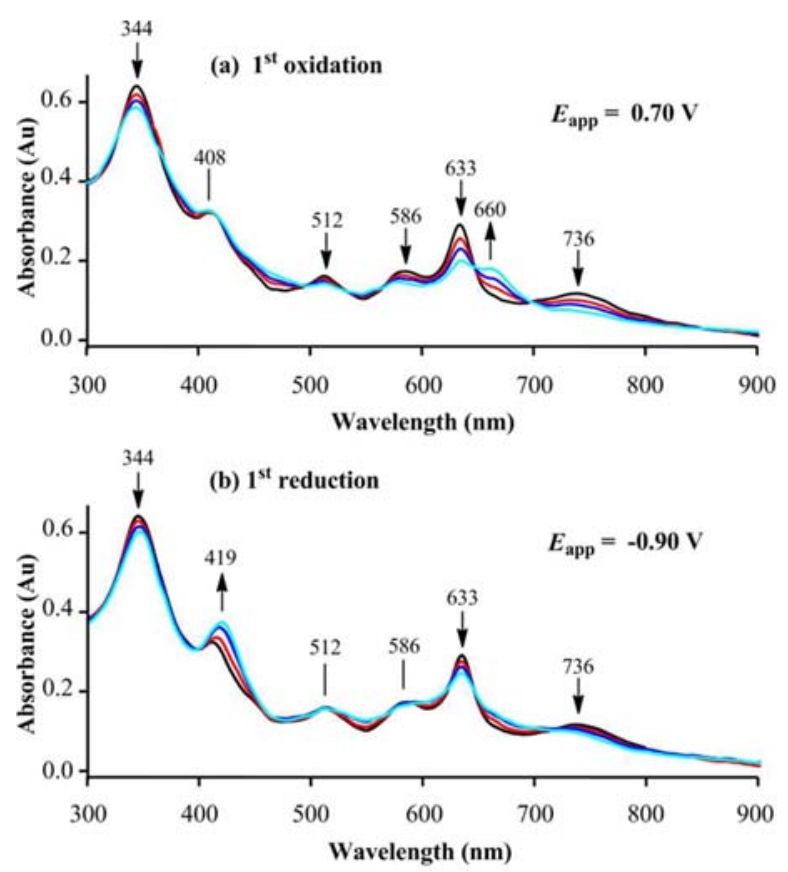

Figure 3. UV-vis spectral changes of TD-2 during (a) the first oxidation at $0.70 \mathrm{~V}$ and $(\mathrm{b})$ the first reduction at $-0.90 \mathrm{~V}$ in $\mathrm{PhCN}$ with $0.1 \mathrm{M}$ TBAP.

which show UV-vis spectra obtained during the first oneelectron oxidation and first one-electron reduction of TD-2 TD-1, TD-3, and TD-4, respectively.

For TD-2, the band at $408 \mathrm{~nm}$ of the neutral compound is attributed to the porphyrin Soret band, in part on the basis of the analysis of electronic absorption spectra of the monomeric porphyrin precursor, $7 \mathbf{a}$ or $\mathbf{7 b}$ (Figure S6 in the Supporting Information), and in part on previous assignments of the absorption bands in the literature. ${ }^{19-21}$ This band in the tripledeckers remained almost unchanged in intensity and position after the first one-electron oxidation at an applied potential of $0.70 \mathrm{~V}$ (Figure 3a), which suggests that the first oxidation of TD-2 is located in large part on one or both of the phthalocyanine macrocycles in the triple-decker compounds. This assignment is also consistent with the observed changes in the phthalocyanine bands of the neutral compound as the reaction proceeds. The bands of the neutral compound at 344, 512 , and $586 \mathrm{~nm}$ in PhCN decrease in intensity during the first oxidation, as seen in Figure $3 \mathrm{a}$. The Q band at $633 \mathrm{~nm}$, which is assigned to the Pc macrocycle (see Table 1), also decreases significantly in intensity and is replaced by a new band at 660 $\mathrm{nm}$ in the one-electron-oxidized compound.

Although the porphyrin Soret band of the neutral compound at $408 \mathrm{~nm}$ increases in intensity and shifts to $419 \mathrm{~nm}$ during the first reduction (Figure $3 \mathrm{~b}$ ), the overall spectral changes during the first reduction are attributed to a phthalocyanine-based reaction, in large part on the basis of the fact that the two bands at 344 and $633 \mathrm{~nm}$, which are assigned to the Pc macrocycles, both decrease in intensity. This is consistent with conclusions from the above analysis of the electrochemical data and indicates that one or both phthalocyanine macrocycles are the predominant site of the first electron addition. Similar spectral changes are observed for TD-1, TD-3, and TD-4 during the first oxidation and first reduction in PhCN (see Figures S7-S9 in the Supporting Information).

Magnetism. The direct current $(\mathrm{dc})$ magnetic properties of the isostructural triple-deckers $\mathrm{Tb}_{2}$ (TD-3) and $\mathrm{Dy}_{2}$ (TD-4) were measured on microcrystalline powder samples and were studied between 1.8 and $300 \mathrm{~K}$ under an applied field of 1000 Oe. Plots of $\chi_{M} T$ vs $T$ are given in Figure 4 . The $\chi_{M} T$ value of

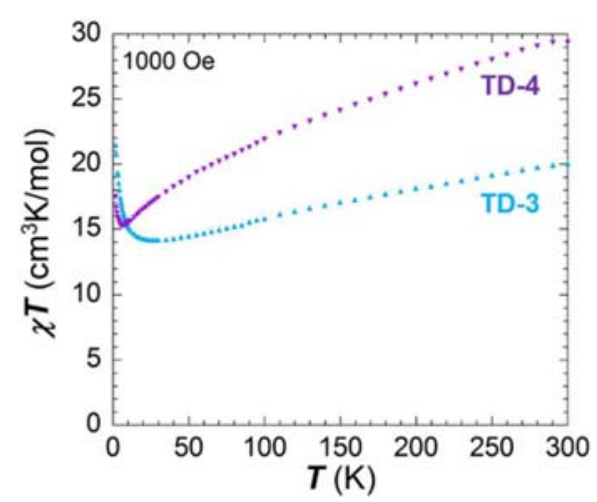

Figure 4. Temperature dependence of the $\chi_{\mathrm{M}} T$ product at 1000 Oe for $\mathrm{Tb}_{2}$ (TD-3) (turquoise) and $\mathrm{Dy}_{2}$ (TD-4) (purple).

$20.06 \mathrm{~cm}^{3} \mathrm{~K} / \mathrm{mol}$ for the $\mathrm{Tb}^{\mathrm{III}}$ containing complex TD-3 is in good agreement $\left(S=6 / 2,{ }^{7} \mathrm{~F}_{6}, g=3 / 2, C=11.82 \mathrm{~cm}^{3} \mathrm{~K} /\right.$ $\mathrm{mol})^{22}$ with the expected value of $23.64 \mathrm{~cm}^{3} \mathrm{~K} / \mathrm{mol}$. The $\chi_{\mathrm{M}} T$ value of $29.35 \mathrm{~cm}^{3} \mathrm{~K} / \mathrm{mol}$ for the $\mathrm{Dy}_{2}$ complex (TD-4) at room temperature is in good agreement with what is expected for two independent Dy ${ }^{\mathrm{III}}\left(S=5 / 2,{ }^{6} \mathrm{H}_{15 / 2}, g=4 / 3, C=14.17 \mathrm{~cm}^{3} \mathrm{~K} /\right.$ $\mathrm{mol})^{23}$ ions $\left(28.34 \mathrm{~cm}^{3} \mathrm{~K} / \mathrm{mol}\right)$. It is interesting to compare the magnetic behavior of these two isostructural compounds which contain non-Kramers (TD-3) versus Kramers ions (TD-4). The behavior of the Dy ${ }^{\text {III }}$-containing compound TD-4 is discussed first in this comparison.

When the temperature is lowered, the $\chi_{\mathrm{M}} T$ product of TD-4 decreases steadily until it reaches a minimum value of 15.30 $\mathrm{cm}^{3} \mathrm{~K} / \mathrm{mol}$ at $6.65 \mathrm{~K}$. On further cooling, the $\chi_{\mathrm{M}} T$ value sharply increases to reach a value of $17.47 \mathrm{~cm}^{3} \mathrm{~K} / \mathrm{mol}$ at $1.8 \mathrm{~K}$. For the complex TD-3, the decrease of the $\chi_{\mathrm{M}} T$ product when the temperature is lowered is much smaller and the minimum appears much earlier, at $28.0 \mathrm{~K}$, with a value of $14.16 \mathrm{~cm}^{3} \mathrm{~K}$ / 

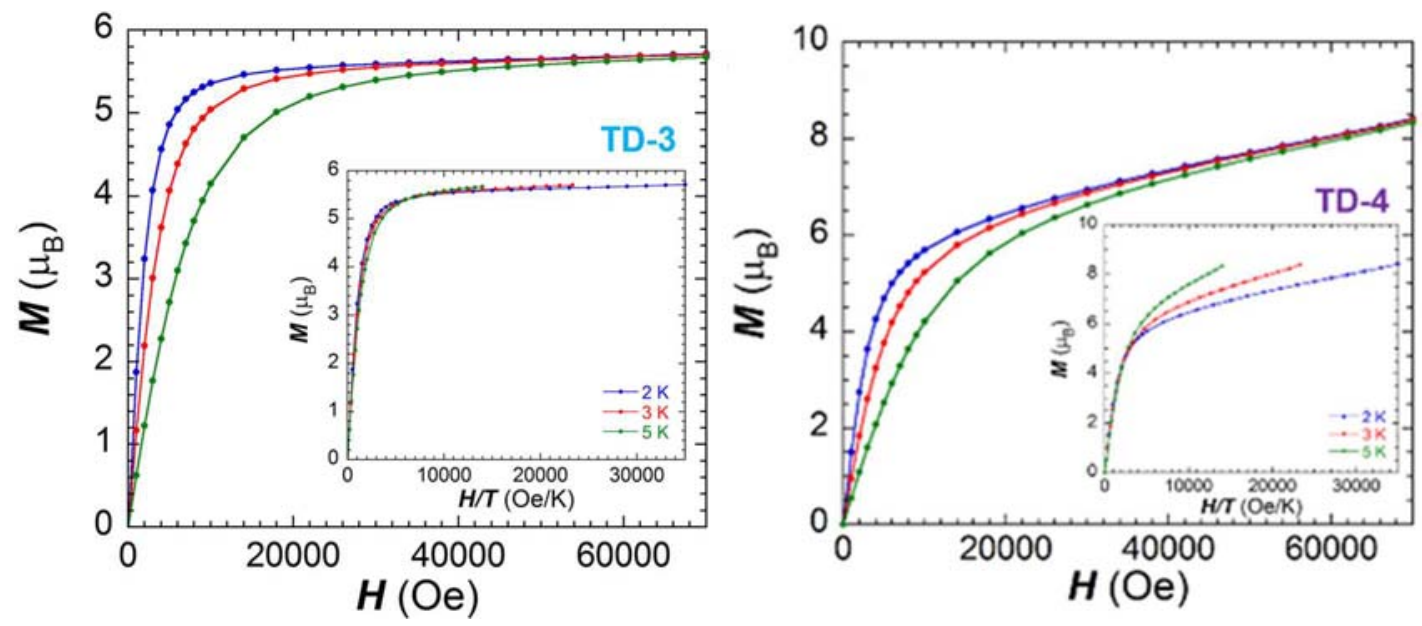

Figure 5. Magnetization curves measured between 0 and $7 \mathrm{~T}$ at different temperatures for (left) $\mathrm{Tb}_{2}$ (TD-3) and (right) $\mathrm{Dy} \mathrm{y}_{2}$ (TD-4) and the reduced magnetizations as insets for each $(2,3$, and $5 \mathrm{~K}$; lines are given as guides to the eyes).
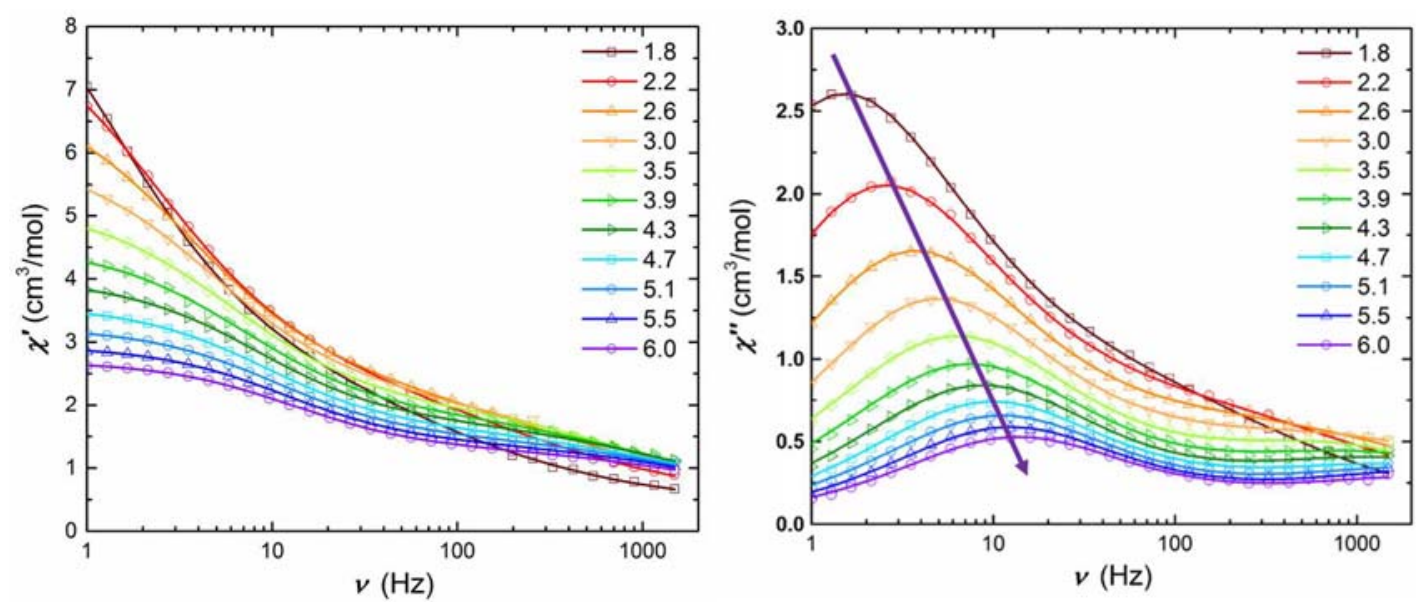

Figure 6. Frequency dependence of the in-phase $\chi_{\mathrm{M}}{ }^{\prime}$ (left) and out-of-phase susceptibility $\chi_{\mathrm{M}}{ }^{\prime \prime}$ (right) for $\mathrm{Tb}_{2}$ (TD-3) under an applied dc field of $0.1 \mathrm{~T}$ in a range between 1.8 and $6.0 \mathrm{~K}$. The solid lines are the best simultaneous fits of $\chi_{\mathrm{M}}^{\prime}$ (left) and $\chi_{\mathrm{M}}{ }^{\prime \prime}$ (right) within the whole frequency range for two relaxation processes (see eqs 1 and 2 in the Supporting Information). The purple arrow highlights the first relaxation process.

mol. Upon further cooling, the $\chi_{\mathrm{M}} T$ product for TD-3 sharply increases, as also seen for TD-4, and reaches a value of 20.06 $\mathrm{cm}^{3} \mathrm{~K} / \mathrm{mol}$ at $1.8 \mathrm{~K}$. This behavior is indicative of ferromagnetic interactions between the $\mathrm{Ln}^{\mathrm{III}}$ ions, as previously shown by Ishikawa and co-workers through a comparative study of PcLnPcYPc-type and homodinuclear PcLnPcLnPctype triple-decker complexes, mediated not by exchange but rather by magnetic dipolar coupling. ${ }^{3 \mathrm{~b}-\mathrm{d}}$

The field dependence of the magnetization (Figure 5) was measured between 2.0 and $5.0 \mathrm{~K}$. For compound $\mathrm{Dy}_{2}$ (TD-4) the lack of saturation in the magnetization values indicates the presence of significant magnetic anisotropy and/or low-lying excited states. The magnetization measurements for compound TD-4 show no saturation up to $7 \mathrm{~T}$, and the values of the isotherms rapidly increase at low field before following a more gradual linear increase after $1.0 \mathrm{~T}$ without saturation. The anisotropy present in this compound is seen from the reduced magnetization plots shown as $M$ vs $H / T$ (Figure 5 right, inset) which clearly do not superpose onto a single master curve. On the other hand, for compound TD-3, the isostructural $\mathrm{Tb}^{\mathrm{III}}$ complex, the magnetization shows a rapid increase in the magnetization at low magnetic fields, reaching a clear saturation above $1.0 \mathrm{~T}$ and the reduced magnetization shown as $M$ vs $H / T$
(Figure 5 left, inset), essentially shows a superposition of the three isotherms onto one master curve.

The behavior of both compounds is very similar to what was observed previously for $(\mathrm{Pc}) \operatorname{Ln}(\mathrm{Pc}) \operatorname{Ln}(\mathrm{Pc})$-type homo- and heterodinuclear $\mathrm{Tb}$ triple-decker systems. ${ }^{3 \mathrm{e}}$ However, there the magnetization behavior for the $\mathrm{Tb}$ analogue was interpreted in terms of non-negligible magnetic anisotropy and/or low-lying excited states, but we prefer to regard the current $\mathrm{Tb}$ system as essentially isotropic in terms of its magnetization behavior. The values of the magnetization at $7 \mathrm{~T}$ and $2 \mathrm{~K}$ are $5.71 \mu_{\mathrm{B}}$ for $\mathrm{Tb}_{2}$ (TD-3) and $8.41 \mu_{\mathrm{B}}$ for $\mathrm{Dy}_{2}$ (TD-4).

In order to investigate the presence of slow relaxation of the magnetization which may originate from SMM behavior, ac magnetic susceptibility measurements were performed on compounds TD-3 and TD-4. In attempts to suppress any quantum tunneling of the magnetization (QTM), the frequency-dependent ac susceptibility was measured for both complexes with a varying applied field (Figure S10 in the Supporting Information). Although other $\mathrm{Tb}^{\mathrm{III}}$ triple-decker compounds can show ac signals without the need for applying a field, ${ }^{3 \mathrm{~d}}$ in this case, for TD-3, the optimum dc field where the quantum tunneling is smallest was found to be $1000 \mathrm{Oe}$. In the case of the $\mathrm{Dy}_{2}$ triple-decker (TD-4) an optimum field could 
not be determined, as evidenced by the very weak out-of-phase signal, which suggests that suppression of QTM is not possible using the available parameters of the SQUID magnetometer.

The ac measurements, carried out under a dc field of 1000 Oe for $\mathrm{Tb}_{2}$ (TD-3) (Figure 6), reveal out-of-phase maxima in the range of $1.8-6.0 \mathrm{~K}$. These maxima, highlighted with a purple arrow, were used to extract the relaxation time as a function of the temperature. Additionally, temperature-dependent ac measurements were performed (see Figure S11 in the Supporting Information), to investigate the dynamic magnetic processes. Temperature-dependent signals are visible for frequencies higher than $100 \mathrm{~Hz}$ in the temperature range from 9.0 to $13.0 \mathrm{~K}$. The maxima could be extracted and were used to calculate the energy barrier (Figure 7). Both extracted

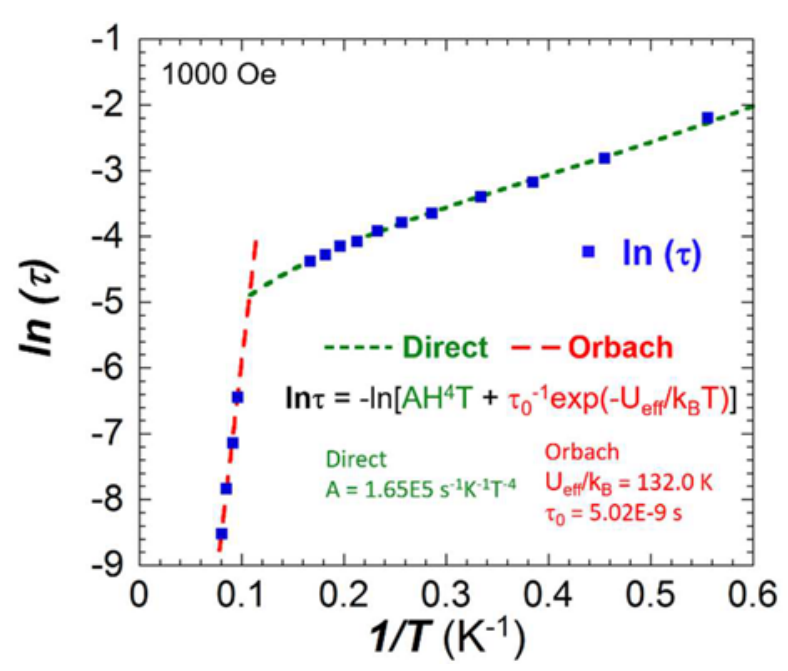

Figure 7. Plot of $\ln \tau$ versus $1 / T$ for $\mathrm{Tb}_{2}$ (TD-3) under an applied field of 1000 Oe. The dashed green line represents the best fit of a direct process and the dashed red line the best fit of the Orbach process.

maxima were plotted as $\ln \tau$ versus $1 / T$ in order to gain insight into the dynamics of the relaxation processes. There are two distinctly visible regimes, which can be fitted by using eq $1,{ }^{24}$ which takes only a direct and an Orbach process into account.

$$
\tau^{-1}(T, H)=A H^{4} T+\tau_{0}^{-1} \exp \left(\frac{U_{\text {eff }}}{k_{\mathrm{B}} T}\right)+\mathrm{QTM}
$$

In eq 1 , the $A H^{4} T$ term defines the direct relaxation process for Kramers ions and the second exponential term defines the Orbach process, where the magnetization of the system decays through the thermally activated population of the Kramers doublet. The last term originates from QTM between the two sides of the magnetic anisotropy barrier and is normally only used for zero-static-field data. ${ }^{25,26}$ In order to reduce overparametrization, this contribution has not been estimated. The presence of an Orbach process is more important in characterizing an SMM, because it allows a spin to reorient by climbing over the anisotropy barrier, $U_{\text {eff. }}$.

The high-temperature regime is dominated by an exponential process, that is, a two-phonon Orbach process via a real intermediate state, or thermally assisted quantum tunnelling of the magnetization (TA-QTM), resulting from spin-lattice interactions. ${ }^{23}$ At low temperatures a direct process dominates. The fit of the data in Figure 7 gives $A=1.65 \times 10^{5} \mathrm{~s}^{-1} \mathrm{~K}^{-1} \mathrm{~T}^{-4}$, $U_{\text {eff }} / k_{\mathrm{B}}=132.0 \mathrm{~K}$, and $\tau=5.0 \times 10^{-9} \mathrm{~s}$.
The Cole-Cole plots of $\chi_{\mathrm{M}}^{\prime}$ versus $\chi_{\mathrm{M}}{ }^{\prime \prime}$ for $\mathrm{Tb}_{2}$ (TD-3) between 1.8 and $6.0 \mathrm{~K}$ (Figure 8 ) reveal that there are actually

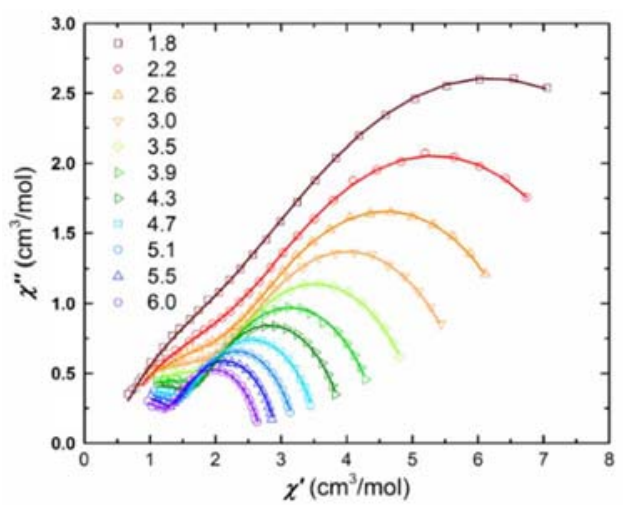

Figure 8. Cole-Cole plot of $\mathrm{Tb}_{2}$ (TD-3) between 1.8 and $6.0 \mathrm{~K}$ and a frequency range between 1 and $200 \mathrm{~Hz}$. Solid lines are fits of the experimental data.

two relaxation processes in the measured temperature range, with profiles typical for the presence of these. ${ }^{27}$ The first process, which we have already identified from the Arrhenius analysis of the data, is related to the set of complete semicircles. Additionally, at small $\chi_{\mathrm{M}}{ }^{\prime}$ and small $\chi_{\mathrm{M}}{ }^{\prime \prime}$ values the beginning of a second relaxation process appears, which is also in line with the data obtained by Holmberg et al. on their $\mathrm{Tb}$ compound, although they chose to concentrate only on the first process ${ }^{3 e}$ (see the Supporting Information of ref $3 \mathrm{e}$ ). Here we were able to fit the $\chi_{\mathrm{M}}^{\prime}$ and $\chi_{\mathrm{M}}{ }^{\prime \prime}$ data simultaneously for the two processes in order to constrain the variable parameters using a generalized Debye model. $^{27 b, 28}$

The extracted $\tau$ values were used to calculate the energy barrier for both processes. Using an Arrhenius fit for the first process leads to an energy barrier of $U_{\text {eff, } 1}=5.7 \mathrm{~K}$ and $\tau=5.1 \times$ $10^{-3} \mathrm{~s}(R=0.999)$ (Figure $\mathrm{S} 12$ in the Supporting Information). This is in good agreement with data extracted from the ac experiment, with only a small deviation in the energy barrier of $0.3 \mathrm{~K}$. The $\tau_{0}$ fit of the second relaxation process gives an energy barrier of $U_{\text {eff, } 2}=12.4 \mathrm{~K}$ and $\tau=5.41 \times 10^{-6} \mathrm{~s}(R=$ 0.998 ) (Figure S12), at a temperature range between 3.0 and $6.0 \mathrm{~K}$. These results are consistent with the fact that at low temperatures, in the case of the non-Kramers ion $\mathrm{Tb}^{\mathrm{III}}$, only the ${ }^{7} \mathrm{~F}_{6}$ ground state is populated, which is well separated from the first excited state, leading to QTM as the major relaxation process when no field is applied. Upon application of a dc field of 1000 Oe, barrier-dependent processes, which are faster than the QTM and direct process, take place. The first process at low frequencies in the range $1-200 \mathrm{~Hz}$ where the linear curve fit of the $\ln \tau$ versus $1 / T$ data suggests that a direct process is operative in this range. The second relaxation process takes place at higher frequencies, and the energy barrier and relaxation time were extracted from the Cole-Cole fit, in the range 3.0-6.0 K, where the data conform to a $1 / \tau \propto T^{7}$ behavior typical for a non-Kramers system (Figure S13 in the Supporting Information), which is in line with a dominant

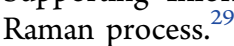

STM Imaging. The triple-decker complexes TD-3 with four undecyl groups $\left(\mathrm{C}_{11} \mathrm{H}_{23}\right)$ and TD-5 with four hexadecyl groups $\left(\mathrm{C}_{16} \mathrm{H}_{23}\right)$ on the macrocyclic porphyrin were chosen to study their self-assembly behavior on a highly oriented pyrolytic graphite (HOPG) surface for imaging by scanning tunneling 
microscopy (STM) at the liquid-solid interface. For comparison, self-assemblies of the free porphyrins $7 \mathbf{b}, \mathbf{c}$ were also imaged under similar conditions.

In both cases, no stable supramolecular networks could be observed under the imaging conditions, as shown in Figure S14 in the Supporting Information for the two triple-decker complexes. However, with regard to the two free base porphyrins, stable supramolecular networks could be imaged, identical with those previously reported. ${ }^{19}$

Sandwich double- and triple-deckers can be observed in a straightforward way on a metal surface by STM at low temperature, ${ }^{30}$ but there have been few reports for roomtemperature imaging at the HOPG/liquid interface, ${ }^{31}$ although under these latter conditions, no particular care was required for sample preparation and imaging conditions. Supramolecular self-assembly on surfaces is usually the result of a delicate balance between intermolecular and molecule-substrate interactions. Janus tectons ${ }^{32}$ can in principle adsorb in various lying-up or upside-down configurations, which can result in very different adsorption energies. ${ }^{33}$ The currently examined triple-deckers, TD-3 and TD-5, were specially designed to adsorb on the porphyrin side due to the presence of the long alkyl chains that are usually most favorable for adsorption on HOPG. ${ }^{19}$ Nevertheless, we cannot exclude here the possibility of other adsorption configurations, with the upper phthalocyanine lying down or standing up on the side, thus prohibiting the formation of stable ordered networks.

\section{CONCLUSION}

In summary, five novel rare-earth heteroleptic porphyrin phthalocyanine triple-decker complexes with bulky peripheral groups were successfully prepared by a microwave-mediated synthesis in medium yields and characterized by electrochemical and spectroelectrochemical techniques. On the basis of the measured redox potentials, the electronic absorption spectra of the initial compounds, and the measured spectral changes during the first oxidation/reduction reactions, the initial sites of oxidation and reduction were both assigned as being phthalocyanine-based. The magnetic properties of the $\mathrm{Tb}_{2}$ (TD-3) and $\mathrm{Dy}_{2}$ (TD-4) compounds reveal ferromagnetic interactions shown by the susceptibility measurements which are caused by magnetic dipolar interactions. The $\mathrm{Tb}$ analogue, TD-3, shows SMM behavior under an applied field of $1000 \mathrm{Oe}$, where the direct and Orbach processes can be determined, resulting in an energy barrier of $U_{\text {eff }}=132.0 \mathrm{~K}$. Cole-Cole plots reveal typical profiles for the presence of two relaxation processes, where the second relaxation process takes place at higher frequencies and the energy barrier and relaxation time were extracted from the Cole-Cole fit. The data conforms to $1 / \tau \propto T^{7}$, which suggests that the second relaxation process is dominated by a Raman process. Furthermore, these compounds could not form $2 \mathrm{D}$ self-assembled networks on an HOPG surface due to their bulky peripheral groups. Meanwhile, we were unable to construct in silico stable triple-deckers which could be energy minimized. All of our attempts, either at semiempirical levels (which lack an adequate parametrization for lanthanides) or at the DFT level, resulted in nonstable minima. In the absence of accurate geometries we were thus unable to perform reliable calculations to gain insight into the mixing of the Por and Pc transitions within the triple-deckers and depending on the $\mathrm{Ln}$ ion.

\author{
*E-mail for H.-G.J.: hongguangiin08@outlook.com. \\ *E-mail for A.K.P.: annie.powell@kit.edu. \\ *E-mail for K.M.K.: kkadish@uh.edu. \\ *E-mail for T.S.B.: ts.balaban@univ-amu.fr.

\section{ORCID}

Irina A. Kühne: 0000-0003-0006-404X

Annie K. Powell: 0000-0003-3944-7427

Karl M. Kadish: 0000-0003-4586-6732

\section{ACKNOWLEDGMENTS}

H.-G. J. gratefully acknowledges his Ph.D. fellowship from the the China Scholarship Council. The Aix Marseille University and the CNRS are thanked for refurbishing our Chirosciences laboratories within the $i S m 2$. Financial support from the Robert A. Welch Foundation (K.M.K., Grant E-680) and the A*MIDEX project (np. ANR-11-IDEX-0001-02) funded by the "Investissements d'Avenir" French Government program, managed by the French National Research Agency (ANR), is acknowledged. I.A.K. and A.K.P. acknowledge the DFG SFB TR88 3MET and the Helmholtz Gemeinschaft POF STN for financial support.

\section{REFERENCES}

(1) (a) Liu, Z.; Yasseri, A. A.; Lindsey, J. S.; Bocian, D. F. Molecular memories that survive silicon device processing and real-world operation. Science 2003, 302, 1543-1545. (b) Wei, L.; Padmaja, K.; Youngblood, W. J.; Lysenko, A. B.; Lindsey, J. S.; Bocian, D. F. Diverse redox-active molecules bearing identical thiol-terminated tripodal tethers for studies of molecular information storage. J. Org. Chem. 2004, 69, 1461-1469. (c) Schweikart, K.-H.; Malinovskii, V. L.; Yasseri, A. A.; Li, J.; Lysenko, A. B.; Bocian, D. F.; Lindsey, J. S. Synthesis and characterization of bis (S-acetylthio)-derivatized europium triple-decker monomers and oligomers. Inorg. Chem. 2003, 42, 7431-7446.

(2) (a) Kong, X.; Zhang, X.; Gao, D.; Qi, D.; Chen, Y.; Jiang, J. Airstable ambipolar field-effect transistor based on a solution-processed octanaphthoxy-substituted tris(phthalocyaninato) europium semiconductor with high and balanced carrier mobilities. Chem. Sci. 2015, 6, 1967-1972. (b) Kan, J.; Chen, Y.; Qi, D.; Liu, Y.; Jiang, J. Highperformance air-stable ambipolar organic field-effect transistor based on tris (phthalocyaninato) europium (III). Adv. Mater. 2012, 24, 1755-1758. (c) Lu, G.; Chen, Y.; Zhang, Y.; Bao, M.; Bian, Y.; Li, X.; Jiang, J. Morphology controlled self-Assembled nanostructures of sandwich mixed (phthalocyaninato) (porphyrinato) Europium tripledeckers. Effect of hydrogen bonding on tuning the intermolecular interaction. J. Am. Chem. Soc. 2008, 130, 11623-11630.

(3) (a) Sakaue, S.; Fuyuhiro, A.; Fukuda, T.; Ishikawa, N. Dinuclear single-molecule magnets with porphyrin-phthalocyanine mixed tripledecker ligand systems giving SAP and SP coordination polyhedra. Chem. Commun. 2012, 48, 5337-5339. (b) Katoh, K.; Kajiwara, T.; Nakano, M.; Nakazawa, Y.; Wernsdorfer, W.; Ishikawa, N.; Breedlove, B. K.; Yamashita, M. Magnetic relaxation of single-molecule magnets 
in an external magnetic field: an Ising dimer of a terbium(III)phthalocyaninate triple-decker complex. Chem. - Eur. J. 2011, 17, 117122. (c) Ishikawa, N.; Iino, T.; Kaizu, Y. Study of ${ }^{1}$ H-NMR spectra of dinuclear complexes of heavy lanthanides with phthalocyanines based on separation of the effects of two paramagnetic centers. J. Phys. Chem. A 2003, 107, 7879-7884. (d) Ishikawa, N.; Otsuka, S.; Kaizu, Y. The effect of the f-f Interaction on the dynamic magnetism of a coupled $4 f^{8}$ system in a dinuclear terbium complex with phthalocyanines. Angew. Chem., Int. Ed. 2005, 44, 731-733. (e) Holmberg, R. J.; Polovkova, M. A.; Martynov, A. G.; Gorbunova, Y. G.; Murugesu, M. Impact of the coordination environment on the magnetic properties of singlemolecule magnets based on homo- and hetero-dinuclear terbium(III) heteroleptic tris(crownphthalocyaninate). Dalton Trans. 2016, 45, 9320-9327.

(4) Schweikart, K.-H.; Malinovskii, V. L.; Diers, J. R.; Yasseri, A. A.; Bocian, D. F.; Kuhr, W. G.; Lindsey, J. S. Design, synthesis, and characterization of prototypical multistate counters in three distinct architectures. J. Mater. Chem. 2002, 12, 808-828.

(5) Chabach, D.; De Cian, A.; Fischer, J.; Weiss, R.; Bibout, M. E. M. Mixed-metal triple-decker sandwich complexes with the porphyrin/ phthalocyanine/porphyrin ligand system. Angew. Chem., Int. Ed. Engl. 1996, 35, 898-899.

(6) (a) Gryko, D.; Li, J.; Diers, J. R.; Roth, K. M.; Bocian, D. F.; Kuhr, W. G.; Lindsey, J. S. Studies related to the design and synthesisof a molecular octal counter. J. Mater. Chem. 2001, 11, 11621180. (b) Gross, T.; Chevalier, F.; Lindsey, J. S. Investigation of rational syntheses of heteroleptic porphyrinic lanthanide (europium, cerium) triple-decker sandwich complexes. Inorg. Chem. 2001, 40, $4762-4774$.

(7) (a) Lu, J.; Deng, Y.; Zhang, X.; Kobayashi, N.; Jiang, J. Optically active mixed (phthalocyaninato) (porphyrinato) rare earth tripledecker complexes. Synthesis, spectroscopy, and effective chiral information transfer. Inorg. Chem. 2011, 50, 2562-2567. (b) Zhu, P.; Pan, N.; Li, R.; Dou, J.; Zhang, Y.; Cheng, D. Y.; Wang, D.; Ng, D. K.; Jiang, J. Electron-donating alkoxy-group-driven synthesis of heteroleptic tris (phthalocyaninato) lanthanide (III) triple-deckers with symmetrical molecular structure. Chem. - Eur. J. 2005, 11, 14251432.

(8) (a) Mannini, M.; Bertani, F.; Tudisco, C.; Malavolti, L.; Poggini, L.; Misztal, K.; Menozzi, D.; Motta, A.; Otero, E.; Ohresser, P.; Sainctavit, P.; Condorelli, G. G.; Dalcanale, E.; Sessoli, R. Magnetic behaviour of $\mathrm{TbPc}_{2}$ single-molecule magnets chemically grafted on silicon surface. Nat. Commun. 2014, 5, 4582. (b) Heutz, S.; Mitra, C.; Wu, W.; Fisher, A. J.; Kerridge, A.; Stoneham, M.; Harker, A.; Gardener, J.; Tseng, H. H.; Jones, T. S. Molecular thin films: a new type of magnetic switch. Adv. Mater. 2007, 19, 3618-3622. (c) Ishikawa, N.; Sugita, M.; Ishikawa, T.; Koshihara, S.-y.; Kaizu, Y. Lanthanide double-decker complexes functioning as magnets at the single-molecular level. J. Am. Chem. Soc. 2003, 125, 8694-8695. (d) Shang, H.; Zeng, S.; Wang, H.; Dou, J.; Jiang, J. Peripheral substitution: an easy way to tuning the magnetic behavior of tetrakis(phthalocyaninato) dysprosium(III) SMMs. Sci. Rep. 2015, 5, 8838. (e) Wang, H.; Qian, K.; Wang, K.; Bian, Y.; Jiang, J.; Gao, S. Sandwich-type tetrakis(phthalocyaninato) dysprosium-cadmium quadruple-decker SMM. Chem. Commun. 2011, 47, 9624-9626.

(9) Jin, H.-G.; Balaban, M. C.; Chevallier-Michaud, S.; Righezza, M.; Balaban, T. S. Biomimetic self-assembling acylphthalocyanines. Chem. Commun. 2015, 51, 11884-11887.

(10) Plamont, R.; Kikkawa, Y.; Takahashi, M.; Kanesato, M.; Giorgi, M.; Chan Kam Shun, A.; Roussel, C.; Balaban, T. S. Nanoscopic imaging of meso-tetraalkylporphyrins prepared in high yields enabled by montmorrilonite $\mathrm{K} 10$ and $3 \AA$ molecular sieves. Chem. - Eur. J. 2013, 19, 11293-11300.

(11) Jiang, J.; Liu, R. C.; Mak, T. C.; Chan, T. D.; Ng, D. K. Synthesis, spectroscopic and electrochemical properties of substituted bis (phthalocyaninato) lanthanide (III) complexes. Polyhedron 1997, $16,515-520$

(12) Lu, F.-L.; Mao, Y.-J.; Wang, W.-D.; Xiao, C. Synthesis and characterization of new mixed rare earth triple-decker complexes with
$\mathrm{A}_{3} \mathrm{~B}$ type [5-(4-hydroxyphenyl)-10,15,20-tris-(4-octyloxyphenyl)porphyrinato] and phthalocyaninato ligands. Dyes Pigm. 2013, 99, 686-692.

(13) (a) Leznoff, C. C.; Lever, A. B. P. Phthalocyanines: Properties and Applications; VCH: Weinheim, Germany, 1993; Vol. 3, pp 1-305. (b) L'Her, M.; Pondaven, A. In The Porphyrin Handbook; Kadish, K. M., Smith, K. M., Guilard, R., Eds.; Academic Press: San Diego, CA, 2003; Vol. 16, pp 117-169.

(14) (a) The Porphyrin Handbook; Kadish, K. M., Smith, K. M., Guilard, R., Eds.; Academic Press: San Diego, CA, 2000; Vol. 8 (Electron Transfer), pp 1-205. (b) Kadish, K. M.; Royal, G.; Caemelbecke, E. V.; Gueletti, L. In The Porphyrin Handbook; Kadish, K. M., Smith, K. M., Guilard, R., Eds.; Academic Press: San Diego, CA, 2000; Vol. 9, pp 1-419.

(15) Duchowski, J. K.; Bocian, D. F. Spectroscopic characterization of triple-decker lanthanide porphyrin sandwich complexes. Effects of strong.pi..pi. interactions in extended assemblies. J. Am. Chem. Soc. 1990, 112, 8807-8811.

(16) Sun, X.; Li, R.; Wang, D.; Dou, J.; Zhu, P.; Lu, F.; Ma, C.; Choi, C.-F.; Cheng, D. Y. Y.; Ng, D. K. P.; Kobayashi, N.; Jiang, J. Synthesis and characterization of mixed phthalocyaninato and meso-tetrakis(4chlorophenyl)porphyrinato triple-tecker complexes-revealing the origin of their electronic absorptions. Eur. J. Inorg. Chem. 2004, 2004, 3806-3813.

(17) Kaim, W.; Fiedler, J. Spectroelectrochemistry: the best of two worlds. Chem. Soc. Rev. 2009, 38, 3373-3382.

(18) Lu, G.; Li, J.; Jiang, X.; Ou, Z.; Kadish, K. M. Europium tripledecker complexes containing phthalocyanine and nitrophenyl-corrole macrocycles. Inorg. Chem. 2015, 54, 9211-9222.

(19) Ma, P.; Chen, Y.; Sheng, N.; Bian, Y.; Jiang, J. Synthesis, characterization and OFET properties of amphiphilic mixed (phthalocyaninato) (porphyrinato) europium (III) complexes. Eur. J. Inorg. Chem. 2009, 2009, 954-960.

(20) Jiang, J.; Liu, W.; Law, W.-F.; Ng, D. K. P. Heteroleptic tripledecker (phthalocyaninato)-(porphyrinato) europium (III) complexes: synthesis and electrochemical study. Inorg. Chim. Acta 1998, 268, 4953.

(21) Zhu, P.; Zhang, X.; Wang, H.; Zhang, Y.; Bian, Y.; Jiang, J. Ferrocene-decorated (phthalocyaninato) (porphyrinato) double- and triple-decker rare earth complexes: synthesis, structure, and electrochemical properties. Inorg. Chem. 2012, 51, 5651-5659.

(22) Benelli, C.; Gatteschi, D. Magnetism of lanthanides in molecular materials with transition-metal ions and organic radicals. Chem. Rev. 2002, 102, 2369-2388.

(23) (a) Finn, C.; Orbach, R.; Wolf, W. Spin-lattice relaxation in cerium magnesium nitrate at liquid helium temperature: a new process. Proc. Phys. Soc., London 1961, 77, 261-268. (b) Orbach, R. On the theory of spin-lattice relaxation in paramagnetic salts. Proc. Phys. Soc., London 1961, 77, 821-826.

(24) (a) Abragam, A.; Bleaney, B. Electron paramagnetic resonance of transition ions; Oxford University Press: Oxford, U.K., 2012. (b) Zadrozny, J. M.; Atanasov, M.; Bryan, A. M.; Lin, C. Y.; Rekken, B. D.; Power, P. P.; Neeses, F.; Long, J. R. Slow magnetization dynamics in a series of two-coordinate iron (II) complexes. Chem. Sci. 2013, 4, 125-138. (c) Lucaccini, E.; Sorace, L.; Perfetti, M.; Costes, J. P.; Sessoli, R. Beyond the anisotropy barrier: slow relaxation of the magnetization in both easy-axis and easy-plane $\mathrm{Ln}$ (trensal) complexes. Chem. Commun. 2014, 50, 1648-1651. (d) Feng, X.; Liu, J. L.; Pedersen, K. S.; Nehrkorn, J.; Schnegg, A.; Holldack, K.; Bendix, J.; Sigrist, M.; Mutka, H.; Samohvalov, D.; Aguilà, D.; Tong, M.-L.; Long, J. R.; Clérac, R. Multifaceted magnetization dynamics in the mononuclear complex $\left[\mathrm{Re}^{\mathrm{IV}} \mathrm{Cl}_{4}(\mathrm{CN})_{2}\right]^{2-}$. Chem. Commun. 2016, 52, 12905-12908. (e) Atanasov, M.; Zadrozny, J. M.; Long, J. R.; Neese, F. A theoretical analysis of chemical bonding, vibronic coupling, and magnetic anisotropy in linear iron (II) complexes with single-molecule magnet behavior. Chem. Sci. 2013, 4, 139-156.

(25) Sottini, S.; Poneti, G.; Ciattini, S.; Levesanos, N.; Ferentinos, E.; Krzystek, J.; Sorace, L.; Kyritsis, P. Magnetic Anisotropy of Tetrahedral 
$\mathrm{Co}^{\mathrm{II}}$ Single-Ion Magnets: Solid-State Effects. Inorg. Chem. 2016, 55, 9537-9548.

(26) Tang, J.; Zhang, P. Lanthanide single molecule magnets; Springer: Berlin, Heidelberg, 2015.

(27) (a) Rechkemmer, Y.; Fischer, J. E.; Marx, R.; Dörfel, M. A.; Neugebauer, P.; Horvath, S.; Gysler, M.; Brock-Nannestad, T.; Frey, W.; Reid, M. F. Comprehensive spectroscopic determination of the crystal field splitting in an erbium single-ion magnet. J. Am. Chem. Soc. 2015, 137, 13114-13120. (b) Guo, Y.-N.; Xu, G.-F.; Guo, Y.; Tang, J. Relaxation dynamics of dysprosium (III) single molecule magnets. Dalton Trans. 2011, 40, 9953-9963.

(28) (a) Chilton, N. F. "CC-Fit" can be found at http://www. nfchilton.com/cc-fit.html, 2014. (b) Cole, K. S.; Cole, R. H. Dispersion and absorption in dielectrics I. Alternating current characteristics. J. Chem. Phys. 1941, 9, 341-351. (c) Gatteschi, D.; Sessoli, R.; Villain, J. Molecular Nano-magnets; Oxford University Press: Oxford, U.K., 2006.

(29) (a) Katoh, K.; Horii, Y.; Yasuda, N.; Wernsdorfer, W.; Toriumi, K.; Breedlove, B. K.; Yamashita, M. Multiple-decker phthalocyaninato dinuclear lanthanoid (III) single-molecule magnets with dual-magnetic relaxation processes. Dalton Trans. 2012, 41, 13582-13600. (b) Guo, Y.-N.; Xu, G.-F.; Gamez, P.; Zhao, L.; Lin, S.-Y.; Deng, R.; Tang, J.; Zhang, H.-J. Two-step relaxation in a linear tetranuclear dysprosium (III) aggregate showing single-molecule magnet behavior. J. Am. Chem. Soc. 2010, 132, 8538-8539. (c) Liddle, S. T.; van Slageren, J. Improving f-element single molecule magnets. Chem. Soc. Rev. 2015, $44,6655-6669$.

(30) (a) Tanaka, H.; Ikeda, T.; Takeuchi, M.; Sada, K.; Shinkai, S.; Kawai, T. Molecular rotation in self-assembled multidecker porphyrin complexes. ACS Nano 2011, 5, 9575-9582. (b) Katoh, K.; Komeda, T.; Yamashita, M. Surface morphologies, electronic structures, and Kondo effect of lanthanide(III)-phthalocyanine molecules on $\mathrm{Au}(111)$ by using STM, STS and FET properties for next generation devices. Dalton Trans. 2010, 39, 4708-4723. (c) Lodi Rizzini, A.; Krull, C.; Mugarza, A.; Balashov, T.; Nistor, C.; Piquerel, R.; Klyatskaya, S.; Ruben, M.; Sheverdyaeva, P. M.; Moras, P. Coupling of single, double, and triple-decker metal-phthalocyanine complexes to ferromagnetic and antiferromagnetic substrates. Surf. Sci. 2014, 630, 361-374. (d) Katoh, K.; Komeda, T.; Yamashita, M. The frontier of molecular spintronics based on multiple-decker phthalocyaninato $\mathrm{Tb}^{\mathrm{III}}$ singlemolecule magnets. Chem. Rec. 2016, 16, 987-1016.

(31) (a) Otsuki, J.; Komatsu, Y.; Kobayashi, D.; Asakawa, M.; Miyake, K. Rotational libration of a double-decker porphyrin visualized. J. Am. Chem. Soc. 2010, 132, 6870-6871. (b) Otsuki, J.; Kawaguchi, S.; Yamakawa, T.; Asakawa, M.; Miyake, K. Arrays of double-decker porphyrins on highly oriented pyrolytic graphite. Langmuir 2006, 22, 5708-5715. (c) Otsuki, J. STM studies on double-and triple-decker porphyrin and phthalocyanine complexes. Supramol. Chem. 2011, 23, 169-182.

(32) Du, P.; Jaouen, M.; Bocheux, A.; Bourgogne, C.; Han, Z.; Bouchiat, V.; Kreher, D.; Mathevet, F.; Fiorini-Debuisschert, C.; Charra, F. Surface-confined self-assembled Janus tectons: a versatile platform towards the noncovalent functionalization of grapheme. Angew. Chem. 2014, 126, 10224-10230.

(33) Yanagi, H.; Ikuta, K. Stochastic switching of subphthalocyanine arrays triggered by scanning tunneling microscopy. Surf. Sci. 2005, 581, $9-16$ 